\title{
EXPRESSÃO DA FERTILIDADE DE GEMAS DA VIDEIRA EM FUNÇÃO DE DIFERENTES ÉPOCAS DE PODA E DOSES DE NITROGÊNIO
}

\section{EXPRESSION OF BUD FERTILITY OF GRAPEVINE IN FUNCTION OF DIFFERENT PRUNING TIMES AND DOSES OF NITROGEN}

\author{
Carlos Vanzeli BARTH ${ }^{1}$ \\ Ruy Inacio Neiva de CARVALHO² \\ Fabiano SIMÕES ${ }^{3}$
}

\begin{abstract}
RESUMO
Os tratos culturais aplicados ao vinhedo interferem no crescimento vegetativo e reprodutivo de ramos novos da videira. A época de poda e a dose de nitrogênio aplicada antes da brotação natural podem modificar o crescimento vegetativo e a expressão da fertilidade de gemas da videira. Este trabalho teve como objetivo avaliar essa expressão em função de diferentes épocas de poda e doses de nitrogênio. Foi realizada a poda curta hibernal em videiras da cultivar Niagara Rosada, deixando-se nos ramos duas gemas (basal e apical), em três épocas diferentes (precoce, intermediária e tardia), associadas a adubações nitrogenadas com 0,50 e $100 \mathrm{~g}$ de $\mathrm{N}$ por planta. Foram avaliados o número de cachos por gema, percentagem de gemas danificadas, percentagem de gemas dormentes, percentagem de inibição de fertilidade de gemas e vigor de ramos novos. O levantamento da fertilidade real foi realizado em laboratório, comparando-se assim com a fertilidade expressa a campo. Para a melhor expressão da fertilidade de gemas verificou-se que a poda intermediária sem adubação nitrogenada e a poda precoce com adubação nitrogenada de $50 \mathrm{~g}$ de $\mathrm{N}$ por planta estimulou a produção de cachos em ramos oriundos da gema basal do ramo podado. A poda tardia com adubação nitrogenada de $100 \mathrm{~g}$ de $\mathrm{N}$ por planta estimulou a produção de cachos em ramos oriundos da gema apical do ramo podado.
\end{abstract}

Palavras-chave: Vitis labrusca, condução, nitrogênio, frutificação, uva.

\begin{abstract}
The culture treatment applied in the grapevine interferes in vegetative and reproductive growth of new grapevine branches. The period of pruning and doses of nitrogen fertilizer before of natural sprout can modify the vegetative growth and the expression of fertility of grapevine's buds. The objective of this work was to evaluate this expression in function of different periods of pruning and doses of nitrogen. The technical of pruning utilized in 'Niagara Rosada' grapevines was the short hibernal pruning, where two buds were left in the branches (basal and apical), realized in three differents period (early, intermediate and later), associated with nitrogen fertilizer with 0,50 and $100 \mathrm{~g}$ of $\mathrm{N}$ per plant. The number of bunch per bud, percentage of damaged buds, percentage of dormant buds, percentage of inhibition of buds fertility and vigor of new branches were evaluated. The real fertility was evaluated in laboratory and compared with the fertility express in field. The best expression of buds fertility occurred with the intermediated pruning without fertilizer and early pruning with $50 \mathrm{~g} \mathrm{~N}$ per plant for the production of bunch in branches originated from the basal bud of the prunned branch. The later pruning with $100 \mathrm{~g}$ of $\mathrm{N}$ per plant stimulated the production of bunch in branches originated from the apical bud of the prunned branch.
\end{abstract}

Key-words: Vitis labrusca, conduction, nitrogen, fructification, grape.

\footnotetext{
${ }^{1}$ Engenheiro Agrônomo autônomo. Curitiba/PR. agrocarlos@gmail.com;

${ }^{2}$ Eng. Agrônomo, Dr., Professor Titular do Curso de Agronomia, Centro de Ciências Agrárias e Ambientais, PUCPR. BR 376, km 14 CEP 83010-500. São José dos Pinhais, Paraná ruy.carvalho@pucpr.br;

${ }^{3}$ Engenheiro Agrônomo, Mestrando em Fruticultura de Clima Temperado, FAEM-UFPel. Bolsista CAPES. Rua Luiz Braile, 277 B3/404, Três Venda, Pelotas/RS, CEP: 96055-080. simoes.f@gmail.com.
} 


\section{INTRODUÇÃO}

$\mathrm{Na}$ videira não se distinguem gemas vegetativas e gemas floríferas, como em outras frutíferas, mas sim somente gemas mistas, que originam brotos com cachos e folhas ou somente com folhas (MIELE e MANDELLI, 2004). No período de repouso, já estão definidos na gema da videira seus ramos, folhas, gavinhas e cachos (SOUSA, 1996).

O número de cachos constitui-se num dos principais componentes da produtividade sendo determinado pela poda e pela fertilidade das gemas, que é uma medida quantitativa do potencial da planta em produzir frutos. O comportamento da videira em relação à brotação e fertilidade de gemas pode variar segundo a época de poda e a cultivar copa (LEÃO e SILVA, 2003), bem como segundo o porta-enxerto utilizado (PAULETTO et al., 2001a; PAULETTO et al., 2001b; TERRA et al., 2003).

A aplicação de inibidores da síntese de giberelinas em videiras também altera a fertilidade das gemas, mas a resposta é variada de acordo com o produto aplicado. O paclobutrazol resultou na redução da percentagem de gemas férteis da cultivar 'Rubi' (BOTELHO et al., 2004b), enquanto o cycocel promoveu aumento da percentagem de gemas férteis na cultivar 'Itália' (BOTELHO et al., 2004a).

Sem a execução da poda, a produtividade da videira não é constante e os cachos são pequenos e de baixa qualidade. Ao limitar o número e o comprimento dos ramos, a poda proporciona um balanço racional entre o vigor e a produção, regularizando a quantidade e a qualidade da uva produzida (MIELE e MANDELLI, 2004). Nas condições dos parreirais brasileiros a técnica de poda mais utilizada para a videira da cultivar Niagara Rosada é a poda curta deixando-se duas gemas por esporão (SOUSA, 1996).

A capacidade das gemas da videira em se diferenciar é também garantida pela nutrição da planta, na qual o elemento de grande importância é o nitrogênio (SOUSA, 1996). Os produtores ainda não têm consenso no uso da adubação nitrogenada, principalmente devido a uma relação inversa entre excesso de vigor das plantas, produtividade e qualidade dos frutos (MELO, 2004). Na época de brotação da videira a maior parte do nitrogênio necessário ao novo crescimento provém das raízes (BRUNETTO et al., 2005) realçando a importância da adubação nitrogenada nesta fase. A cultivar Niagara Rosada, se não receber adubação, produz ramos finos e pouco produtivos (SOUSA, 1996). Porém, o excesso de adubação nitrogenada desequilibra a relação carbono/nitrogênio, que regula todo o mecanismo da diferenciação e indução das gemas florais, cuja conseqüência é a diminuição da fertilidade das gemas. Com a falta desse elemento as plantas apresentam um desenvolvimento deficiente, resultando numa baixa produção, com cachos pequenos e desuniformes (ALBUQUERQUE, 1996).

Sugeriu-se então a hipótese de que se os tratos culturais aplicados ao vinhedo interferem no crescimento vegetativo e reprodutivo de ramos novos da videira, então a época de poda e a dose de nitrogênio aplicada antes da brotação natural, bem como suas interações, podem modificar o crescimento vegetativo e a expressão da fertilidade de gemas já determinada durante a fase de crescimento vegetativo do ciclo anterior.

Este trabalho teve como objetivo avaliar a expressão da fertilidade de gemas da videira em função de diferentes épocas de poda e diferentes doses de nitrogênio.

\section{METODOLOGIA}

Utilizaram-se videiras de três anos de idade da cultivar Niagara Rosada ( Vitis labrusca) enxertadas em porta-enxerto ' 420 A', conduzidas em sistema de semipérgola em "T" (BIASI et al., 1998), espaçamento $3 \times 5 \mathrm{~m}$ e sem indução forçada de brotação. Foram estudados os efeitos da época da poda e dose de nitrogênio aplicada, bem como suas interações, na expressão da fertilidade de gemas da videira.

A técnica de poda aplicada foi a poda curta hibernal, na qual foram deixadas nos ramos duas gemas, que foi realizada com a planta em repouso. As podas foram realizadas em três épocas distintas: poda precoce em 17 de julho, poda intermediária em 14 de agosto e poda tardia em 28 de agosto.

A adubação nitrogenada foi realizada quando foi constatado o início da brotação, com três doses de nitrogênio (0, 50 e $100 \mathrm{~g}$ de $\mathrm{N}$ por planta). Como fonte de nitrogênio utilizou-se a uréia. Conforme o laudo de análise química do solo e recomendações de adubação de manutenção para a cultura da videira (RAIJ et al., 1985), foram aplicados $2,52 \mathrm{Kg}$ de calcário, $90 \mathrm{~g}$ de $\mathrm{P}_{2} \mathrm{O}_{5}$ e $60 \mathrm{~g}$ de $\mathrm{K}_{2} \mathrm{O}$ por planta, juntamente com a adubação nitrogenada.

Entre 24 de agosto e 15 de setembro foi realizado um levantamento da fertilidade real das gemas de cada planta por meio de contagem do número de primórdios de inflorescência por gema. Segundo método sugerido por Botelho et al. (2004a) e Botelho et al. (2004b), as duas primeiras gemas basais de ramos de um ano foram cortadas na terça parte superior, dessecada e examinada sob estéreo microscópio com aumento de 45 vezes, em laboratório, verificando se havia presença ou não de primórdio de inflorescência. Após a brotação, calculouse a percentagem de primórdios de inflorescências nas amostras de gemas (fertilidade real) que geraram cachos nos ramos novos brotados (fertilidade expressa), por meio da contagem de cachos por ramo novo. Subtraindo de 100 a fertilidade expressa, obtevese a percentagem de inibição de fertilidade de gemas. Foi também determinado o vigor dos ramos, avaliado pelo seu comprimento.

$\mathrm{Na}$ mesma avaliação, realizada no dia 09 de outubro, foi calculado a percentagem de gemas dormentes e danificadas por ação de chuva de granizo ocorrida em 19 de setembro, quando os ramos estavam na fase de plena brotação. Todas as variáveis foram analisadas tanto para a gema basal quanto para 
a gema apical dos ramos podados. As gemas com proximidade inferior a $0,5 \mathrm{~cm}$ da base do ramo podado foram desconsideradas, denominando gema basal a subseqüente às mesmas.

$O$ delineamento experimental utilizado foi o completamente casualizado em um esquema de parcelas subdivididas com três repetições, com o fator dose de nitrogênio nas parcelas principais e o fator época de poda nas subparcelas. A unidade experimental, na qual foram realizadas as contagens, foi formada por $1 / 3$ do total de ramos de uma planta, selecionados com base na uniformidade de vigor. Os dados referentes às gemas basais e apicais do ramo podado foram submetidos à analise estatística separadamente através do programa SANEST (ZONTA e MACHADO, 1984). As médias dos tratamentos com diferenças significativas pelo teste "F" da análise de variância foram comparadas por teste de Tukey (época de poda) ao nível de $5 \%$ de significância e pela análise de regressão (doses de nitrogênio).

\section{RESULTADOS E DICUSSÃO}

Na gema basal dos ramos de videiras que não receberam adubação nitrogenada observa-se que houve diferença significativa para o número de cachos por gema entre as diferentes épocas de poda, em que a maior média foi obtida pela poda intermediária $(1,21$ cachos por gema) diferindo significativamente da poda precoce $(0,51$ cachos por gema). Com relação à percentagem de inibição de fertilidade de gemas, maiores médias foram obtidas por podas precoce e tardia (57,05 e 44,79\%, respectivamente), diferindo significativamente da poda intermediária (3,27\%). Nos parâmetros percentagem de gemas danificadas e gemas dormentes, não foram constatadas diferenças significativas.

Não verificou-se significância para o vigor dos ramos em diferentes épocas de poda (Tabela 1). 0 comprimento médio obtido aos 35 dias após a brotação $(15,1 \mathrm{~cm})$ foi abaixo do determinado por Fracaro et al. (2004b) em parreiral da mesma cultivar em região de baixa ocorrência de frio $(26,9 \mathrm{~cm})$. Além da época de poda e da dose de nitrogênio aplicada, o vigor dos ramos da cultivar Niagara Rosada pode ser influenciado por condições ambientais de temperatura mais elevada ou pela aplicação de produtos sintéticos na planta como o ethephon (FRACARO e PEREIRA, 2004).

Analisando os resultados obtidos para a gema basal foi constatado que, para o tratamento sem adubação nitrogenada a época de poda mais indicada é a intermediária com 3,27\% de inibição da fertilidade das gemas (Figura 1) e com maior índice de cachos por gema (Figura 2).

TABELA 1 - Efeito de diferentes épocas de poda e diferentes doses de nitrogênio sobre a brotação e desenvolvimento da gema basal de ramos podados de videiras da cultivar Niagara Rosada.

\begin{tabular}{|c|c|c|c|c|c|c|c|c|c|}
\hline \multirow[t]{2}{*}{$\begin{array}{c}\text { Doses de } \mathrm{N} \\
\text { (g de } \mathrm{N} \text { por } \\
\text { planta) }\end{array}$} & \multirow{2}{*}{$\begin{array}{c}\text { Época de } \\
\text { poda } \\
\text { Precoce }\end{array}$} & $\begin{array}{l}\text { Número de } \\
\text { cachos por } \\
\text { gema }\end{array}$ & \multicolumn{2}{|c|}{$\begin{array}{c}\text { Gemas } \\
\text { danificadas } \\
(\%)\end{array}$} & \multicolumn{2}{|c|}{$\begin{array}{c}\text { Gemas } \\
\text { dormentes } \\
(\%)\end{array}$} & \multicolumn{2}{|c|}{$\begin{array}{l}\text { Inibição da } \\
\text { fertilidade de } \\
\text { gemas (\%) }\end{array}$} & \multirow{2}{*}{$\begin{array}{c}\text { Vigor de ramos } \\
(\mathrm{cm})\end{array}$} \\
\hline & & $0,51 \quad b$ & 5,03 & $\mathrm{a}$ & 1,83 & $\mathrm{a}$ & 57,05 & $\mathrm{a}$ & \\
\hline \multirow[t]{2}{*}{0} & Interm. & 1,21 a & 15,77 & a & 13,54 & a & 3,27 & $\mathrm{~b}$ & 16,02 \\
\hline & Tardia & $0,65 \mathrm{ab}$ & 22,52 & a & 12,87 & a & 44,79 & $\mathrm{a}$ & 13,56 \\
\hline \multirow{3}{*}{50} & Precoce & 1,09 a & 22,46 & $a$ & 16,01 & $a b$ & 6,47 & $\mathrm{~b}$ & $17,50^{\mathrm{ns}}$ \\
\hline & Interm. & $0,55 \mathrm{a}$ & 4,94 & a & 41,87 & $\mathrm{a}$ & 47,97 & $a b$ & 17,67 \\
\hline & Tardia & $0,55 \mathrm{a}$ & 25,19 & a & 3,27 & $\mathrm{~b}$ & 49,49 & $\mathrm{a}$ & 12,39 \\
\hline \multirow{3}{*}{100} & Precoce & $0,44 a$ & 22,19 & $a$ & 13,68 & $a$ & 62,79 & $a$ & $14,51^{\text {ns }}$ \\
\hline & Interm. & $0,33 a$ & 36,57 & a & 8,55 & a & 68,95 & a & 12,29 \\
\hline & Tardia & $0,22 \mathrm{a}$ & 2,33 & $\mathrm{~b}$ & 7,99 & a & 79,04 & a & 19,05 \\
\hline
\end{tabular}

*Médias seguidas por letras distintas nas colunas diferem entre si pelo teste de Tukey ao nível de $5 \%$ de significância. ${ }^{\text {ns }}$ Não significativo na coluna em cada dose de $\mathrm{N}$.

A interferência da época de poda na fertilidade das gemas também foi determinada em videiras em clima tropical no Vale do São Francisco em Pernambuco e gemas localizadas em posições diferentes no ramo apresentaram respostas distintas, com favorecimento àquelas localizadas mais próximas ao local da poda (LEÃO e SILVA, 2003).

Em gemas basais de videira da cultivar Itália a baixa percentagem de gemas férteis pode ser aumentada pela aplicação de cycocel, um inibidor da síntese de giberelinas (BOTELHO et al., 2004a). Já em videiras da cultivar Rubi a fertilidade das gemas basais não foi melhorada pela aplicação do paclobutrazol (BOTELHO et al., 2004b) mas a aplicação de ácido giberélico reduziu a fertilidade das mesmas (BOTELHO et al., 2004c).

Nas videiras que receberam adubação nitrogenada com $50 \mathrm{~g}$ de $\mathrm{N}$ por planta, tanto para 0 número de cachos por gema quanto para a percentagem de gemas danificadas, não houveram resultados com diferenças significativas em relação à época de poda. Entretanto, foram observadas diferenças na percentagem de inibição de fertilidade de gemas, onde a maior média foi verificada $(49,49$ $\%)$ na poda tardia e menor $(6,47 \%)$ na poda precoce, e na percentagem de gemas dormentes com a maior média na poda intermediária $(41,87 \%)$ e a menor $(3,27 \%)$ na poda tardia (Tabela 1$)$. Assim, para a produção de cachos em ramos oriundos de gema basais de plantas com esta adubação nitrogenada, a poda precoce é a mais indicada por resultar em baixa 
BARTH, C.V. et al. Expressão da fertilidade de gemas...

percentagem de gemas dormentes e menor inibição de fertilidade de gemas. A poda antecipada da videira da cultivar Niagara Rosada também permite a antecipação da colheita de cachos (FERREIRA et al., 2004).

Em cultivos de videira em regiões com inverno ameno em São Paulo, a poda precoce da cultivar Niagara Rosada resultou em boa produtividade e é realizada no período do final de maio ao início de julho (FRACARO et al., 2004a; FRACARO et al., 2004b; PEREIRA e FRACARO, 2004). Em regiões tropicais, videiras da cultivar Itália, que receberam poda longa deixando-se dez gemas por ramo podado, tiveram seu crescimento favorecido quando a poda foi realizada de maio a julho (MURAKAMI et al., 2002).

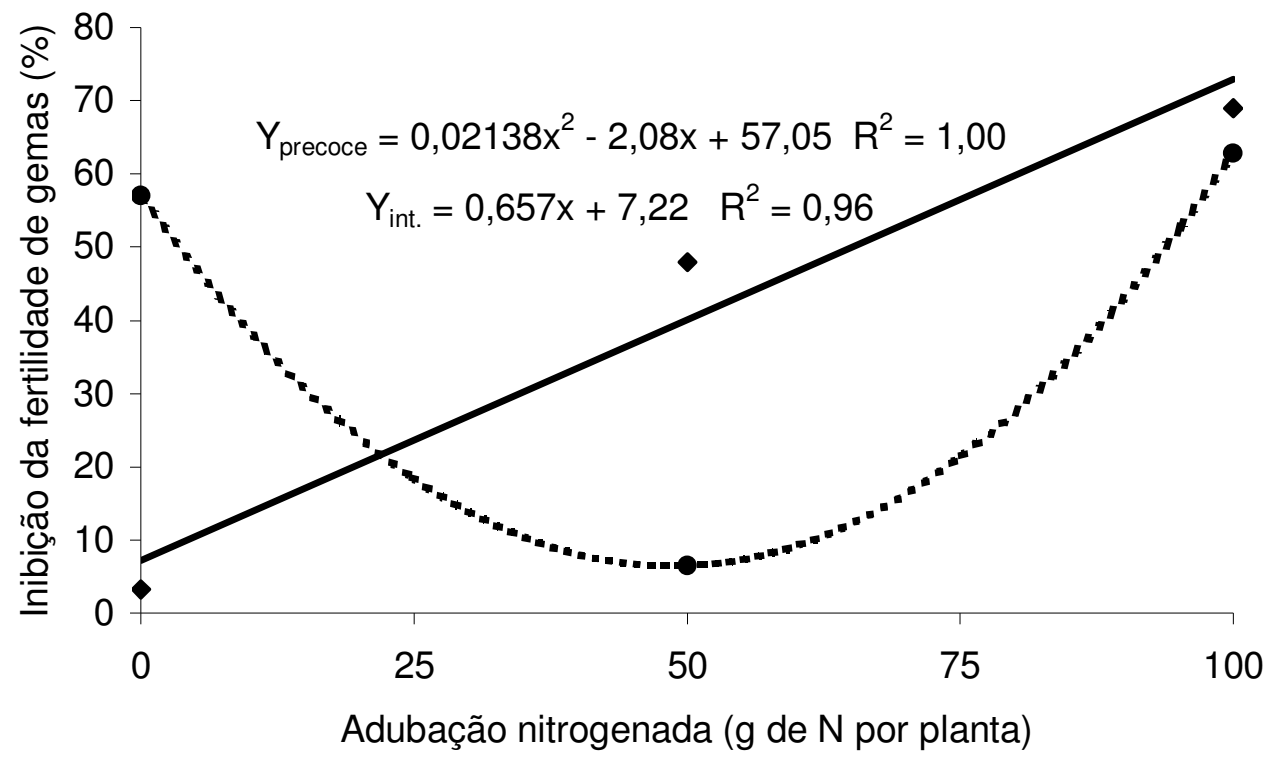

FIGURA 1 - Inibição da fertilidade (\%) em gemas basais de ramos podados de videira da cultivar Niagara Rosada sob efeito de diferentes doses de nitrogênio e épocas de poda (— poda precoce; - poda intermediária). ( $\mathrm{Y}_{\text {tardia }}=$ não significativo).

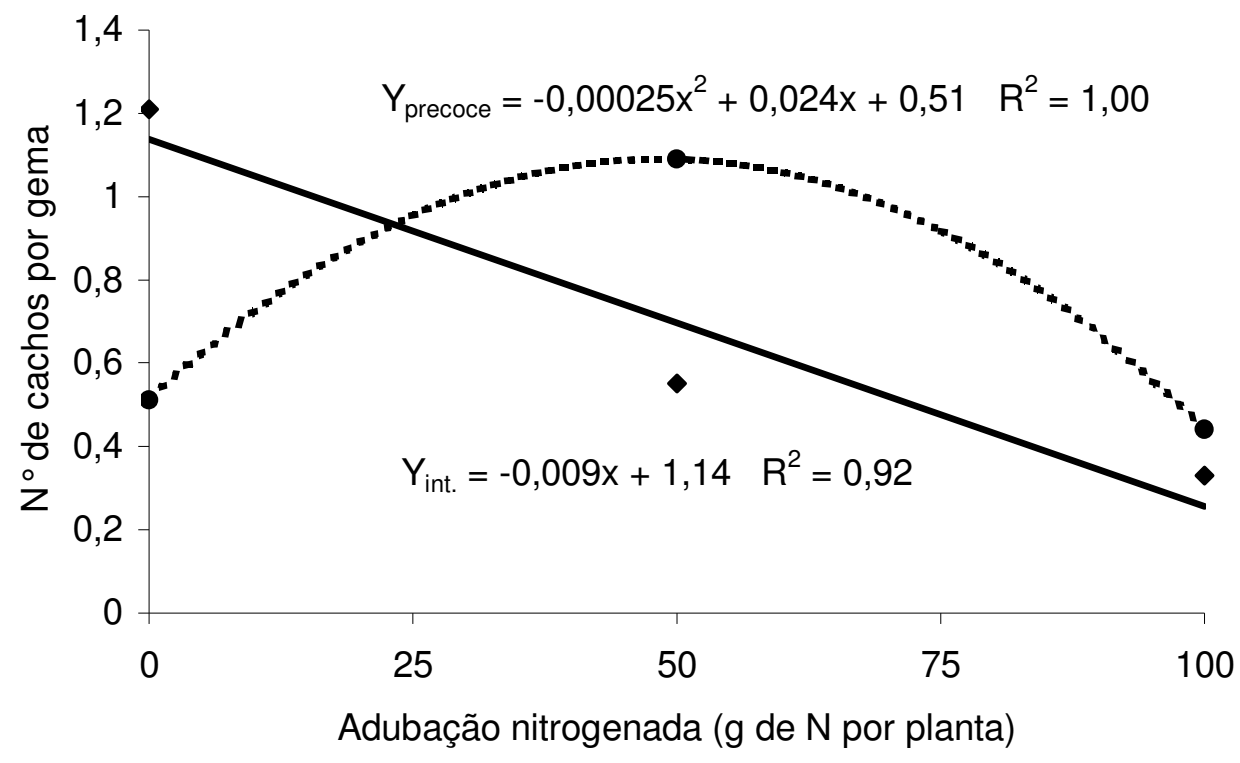

FIGURA 2 - Número de cachos por gema em ramos oriundos da gema basal dos ramos podados de videira da cultivar Niagara Rosada sob efeito de diferentes doses de nitrogênio e diferentes épocas de poda (— poda precoce; — poda intermediária). $\left(\mathrm{Y}_{\text {tardia }}=\right.$ não significativo $)$. 
Para as gemas basais em videiras com adubação nitrogenada de $100 \mathrm{~g}$ de $\mathrm{N}$ por planta, somente para a percentagem de gemas danificadas foram observadas diferenças significativas entre as épocas de poda. As maiores médias foram obtidas nas podas precoce e intermediária $(22,19 \%$ e $36,57 \%$, respectivamente) e a menor (2,33\%) na poda tardia. A antecipação da poda induz a emissão de brotações pelas gemas que passam a receber estímulo da adubação nitrogenada, podendo desenvolver-se mais rapidamente, tornando-se mais expostas a adversidades climáticas precoces. Para os demais parâmetros estudados não foram obtidos resultados com diferenças significativas quanto às épocas de poda. Em relação ao vigor de ramos, não houve interação significativa entre a variável adubação e época de poda.

Analisando os dados obtidos para o tratamento de adubação nitrogenada (100 g de $\mathrm{N}$ por planta) nas condições deste experimento, pode-se constatar que essa adubação não é recomendada para a videira da cultivar Niagara Rosada no que diz respeito à produção de cachos oriundos da gema basal da planta, pois além de possuir uma média de 0,33 cachos por gema esta adubação proporcionou $70,26 \%$ de inibição de fertilidade de gemas (Tabela 1, Figuras 1 e 2).

TABELA 2 - Efeito de diferentes épocas de poda e diferentes doses de nitrogênio sobre a brotação e desenvolvimento da gema apical de ramos podados de videiras da cultivar Niagara Rosada.

\begin{tabular}{|c|c|c|c|c|c|}
\hline $\begin{array}{l}\text { Doses de N } \\
\text { (g de N por } \\
\text { planta) }\end{array}$ & $\begin{array}{c}\text { Epoca } \\
\text { de poda }\end{array}$ & $\begin{array}{c}\text { Número de } \\
\text { cachos por } \\
\text { germa }\end{array}$ & $\begin{array}{c}\text { Gernas } \\
\text { danificadas } \\
(\%)\end{array}$ & $\begin{array}{c}\text { Gernas } \\
\text { dormentes } \\
(\%)\end{array}$ & $\begin{array}{l}\text { Vigor de } \\
\text { ramos (cm)* }\end{array}$ \\
\hline \multirow{3}{*}{0} & Precoce & $0,19^{\mathrm{rr}}$ & $25,87^{\mathrm{mb}}$ & 10,17 & 18,99 a \\
\hline & Inter. & 1,10 & 26,07 & 3,70 & 19,86 a \\
\hline & Tardia & 0,92 & 46,19 & 20,95 & 17,33 a \\
\hline \multirow{3}{*}{50} & Precoce & $0,38^{\mathrm{ng}}$ & $15,49^{\mathrm{mb}}$ & 4,78 & 27,15 a \\
\hline & Inter. & 0,60 & 17,42 & 17,37 & 22,10 a \\
\hline & Tardia & 0,35 & 43,12 & 2,78 & 15,38 a \\
\hline \multirow{3}{*}{100} & Precoce & $0,39^{\mathrm{rz}}$ & $55,36^{\mathrm{Tg}}$ & 8,93 & $17,09 \quad b$ \\
\hline & Inter. & 0,70 & 37,91 & 4,17 & $21,27 \quad b$ \\
\hline & Tardia & 0,47 & 17,17 & 23,90 & 33,24 a \\
\hline
\end{tabular}

*Médias seguidas por letras distintas nas colunas diferem entre si pelo teste de Tukey ao nível de $5 \%$ significância. ${ }^{\text {ns }}$ Não significativo na coluna em cada dose de $\mathrm{N}$.

Na gema apical dos ramos da videira, o único parâmetro em que foi observada interação significativa entre os fatores (adubação e época de poda) foi o vigor de ramos. Plantas adubadas com 0 e $50 \mathrm{~g}$ de $\mathrm{N}$ por planta não apresentaram diferenças significativas entre as épocas de poda, apresentando diferença apenas no tratamento com $100 \mathrm{~g}$ de $\mathrm{N}$ por planta, no qual a maior média $(33,24 \mathrm{~cm})$ foi verificada na poda tardia e as menores nas podas precoce e intermediária $(17,09$ e $21,27 \mathrm{~cm}$, respectivamente) (Tabela 2$)$. O vigor dos ramos da cultivar Niagara Rosada pode ser também influenciado por condições ambientais ou pela aplicação de produtos sintéticos na planta, bem como pelo sistema de sustentação adotado que diferencia a interceptação da radiação solar pela planta (FRACARO e PEREIRA, 2004; PEZZOPANE e PEDRO JUNIOR, 2003).
No que diz respeito à percentagem de inibição de fertilidade de gemas, na gema apical, foi verificada a significância apenas para a variável época de poda, constatando-se diferenças significativas entre a poda tardia com a menor média $(23,68 \%)$ e a poda precoce com a maior média $(69,22 \%)$ (Tabela 3$)$.

Portanto, verificando os resultados obtidos para a gema apical dos ramos da videira, observa-se que a poda mais indicada para estimular produção de cachos em ramos oriundos dessa gema é a poda tardia associada à adubação nitrogenada (100 g de N por planta), pois esta poda obteve $23,68 \%$ de inibição de fertilidade de gemas, independentemente da dose de adubação nitrogenada utilizada e também apresentou o maior vigor quando associada à adubação nitrogenada com $100 \mathrm{~g}$ de $\mathrm{N}$ por planta (Tabela 3 e Figura 3).

TABELA 3 - Efeito de diferentes épocas de poda sobre a inibição da fertilidade de gemas (\%) na gema apical dos ramos podados de videiras da cultivar Niagara Rosada.

\begin{tabular}{lc}
\hline Epoca de poda & ${\text { Inibiçẵo da fertilidade de gemas }(\%)^{*}}^{*}$ \\
\hline Precoce & 69,22 a \\
Intermediária & 47,84 a b \\
Tardia & 23,68 b \\
\hline
\end{tabular}


BARTH, C.V. et al. Expressão da fertilidade de gemas...

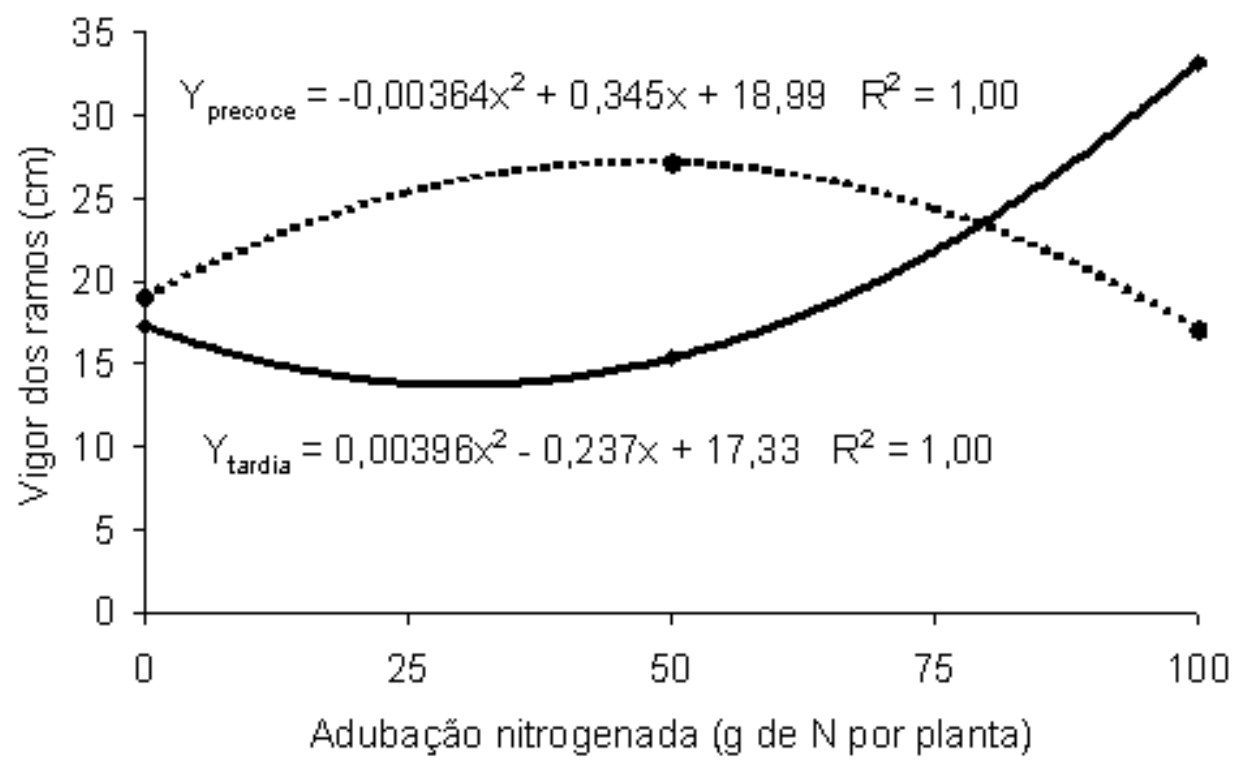

FIGURA 3 - Vigor dos ramos (cm) oriundos de gemas apicais dos ramos podados de videira da cultivar Niagara Rosada sob efeito de diferentes doses de nitrogênio e épocas de poda ( - poda precoce; - poda tardia). ( $\mathrm{Y}_{\text {interm }}=$ não significativo).

\section{CONCLUSÕES}

Para a 'Niagara Rosada' a maior expressão de fertilidade da gema basal do ramo podado foi obtida pela poda intermediária sem adubação nitrogenada e pela poda precoce associada à adubação nitrogenada com $50 \mathrm{~g}$ de $\mathrm{N}$ por planta.

Para a produção de cachos em ramos oriundos da gema apical do ramo podado é recomendada a poda tardia associada à adubação nitrogenada com $100 \mathrm{~g}$ de $\mathrm{N}$ por planta.

\section{REFERÊNCIAS}

1. ALBUQUERQUE, T. C. S. Uva para exportação: aspectos técnicos da produção. Brasília: Embrapa - SPI, 1996. 53p. (Série Publicações Técnicas FRUPEX, 25).

2. BIASI, L. A.; MORIMOTO, F.; ZANETTE, F.; CARVALHO, R. I. N. Trabalhador na fruticultura: implantação do pomar. Curitiba: SENAR-PR, 1998. 31p.

3. BOTELHO, R. V.; PIRES, E. J. P.; TERRA, M. M. Efeitos do cycocel na fertilidade de gemas e no crescimento dos ramos de videiras cv. Itália (Vitis vinifera L.). Revista Brasileira de Fruticultura, Jaboticabal, v.26, n.1, p.78-81, $2004 a$.

4. BOTELHO, R. V.; PIRES, E. J. P.; TERRA, M. M.; MERCER, R. M.; KERNISKI, S. Efeitos do paclobutrazol na fertilidade de gemas e no crescimento dos ramos de videiras cv. Rubi. Revista Brasileira de Fruticultura, Jaboticabal, v.26, n.2, p.345-347, 2004b.

5. BOTELHO, R. V.; PIRES, E. J. P.; TERRA, M. M. Influência do ácido giberélico na fertilidade de gemas e no crescimento dos ramos de videiras cv. Rubi. Revista Brasileira de Agrociência, Pelotas, v.10, n.4, p.439-443, 2004c.

6. BRUNETTO, G.; KAMINSKI, J.; MELO, G. W. B.; GATIBONI, L. C.; URQUIAGA, S. Absorção e redistribuição do nitrogênio em videiras jovens. Revista Brasileira de Fruticultura, Jaboticabal, v.27, n.1, p.110-114, 2005.

7. FERREIRA, E. A.; REGINA, M. A.; CHALFUN, N. N. J.; ANTUNES, L. E. C. Antecipação de safra para videira Niágara Rosada na Região Sul do Estado de Minas Gerais. Ciência e Agrotecnologia, Lavras, v.28, n.6, p.1221-1227, 2004.

8. FRACARO, A. A.; PEREIRA, F. M. Efeito do ethephon sobre a brotação e vigor dos ramos da videira 'Niagara Rosada' (Vitis labrusca L.). Revista Brasileira de Fruticultura, Jaboticabal, v.26, n.3, p.399-402, 2004.

9. FRACARO, A. A.; PEREIRA, F. M.; NACHTIGAL, J. C.; BARBOSA, J. C. Efeito do ethephon sobre a produção da uva 'Niagara Rosada' (Vitis labrusca L.) produzida na entressafra na região de Jales-SP. Revista Brasileira de Fruticultura, Jaboticabal, v.26, n.1, p.82-85, 2004a.

10. FRACARO, A. A.; PEREIRA, F. M.; NACHTIGAL, J. C. Uso do ethephon antes da poda de produção em videira 'Niagara Rosada' (Vitis labrusca L.). Revista Brasileira de Fruticultura, Jaboticabal, v.26, n.1, p.97-100, 2004b.

11. LEÃO, P. C. S.; SILVA, E. E. G. Brotação e fertilidade de gemas em uvas sem sementes no Vale do São Francisco. Revista Brasileira de Fruticultura, Jaboticabal, v.25, n.3, p.375-378, 2003.

12. MELO, G. W. Adubação e manejo do solo para a cultura da videira. Disponível em: <http://www.cnpuv.embrapa.br/servicos/ viticultura/adubvid.html> Acesso em 20 de fev. 2004.

13. MIELE, A.; MANDELLI, F. Poda seca da videira. Disponível em: <http://www.cnpuv.embrapa.br/servicos/viticultura/podaseca.html> Acesso em 20 de fev. 2004. 
14. MURAKAMI, K. R. N.; CARVALHO, A. J. C.; CEREJA, B. S.; BARROS, J. C. S. M.; MARINHO, C. S. Caracterização fenológica da videira cv. Itália (Vitis vinifera L.) sob diferentes épocas de poda na região Norte do Estado do Rio de Janeiro. Revista Brasileira de Fruticultura, Jaboticabal, v.24, n.3, p.611-614, 2002.

15. PAULETTO, D.; MOURÃO FILHO, F. A. A.; KLUGE, R. A.; SCARPARE FILHO, J. A. Produção e vigor da videira 'Niágara Rosada' relacionadas com o porta-enxerto. Pesquisa Agropecuária Brasileira, Brasília, v.36, n.1, p.115-121, 2001a.

16. PAULETTO, D.; MOURÃO FILHO, F. A. A.; KLUGE, R. A.; SCARPARE FILHO, J. A. Efeito do porta-enxerto na qualidade do cacho da videira 'Niágara Rosada'. Pesquisa Agropecuária Brasileira, Brasília, v.36, n.7, p.935-939, $2001 b$.

17. PEREIRA, F. M.; FRACARO, A. A. Efeito do ethephon na qualidade da uva 'Niagara Rosada' (Vitis labrusca L.) produzida na entre-safra, na região de Jales-SP. Revista Brasileira de Fruticultura, Jaboticabal, v.26, n.2, p.254-257, 2004.

18. PEZZOPANE, J. R. M.; PEDRO JUINOR, M. J. Balanço de energia em vinhedo de 'Niagara Rosada'. Bragantia, Campinas, v.62, n.1, p.155-161, 2003.

19. RAIJ, B.; SILVA, N. M.; BATAGLIA, O. C.; QUAGGIO, J. A.; HIROCE, R.; CANTARELLA, H.; BELLINAZZI JUNIOR, R.; DECHEN, A.R.; TRANI, P.E. Recomendações de adubação e calagem para o estado de São Paulo. Campinas: Instituto Agronômico, 1985. 107p. (Boletim Técnico n.100).

20. SOUSA, J. S. I. Uvas para o Brasil. -2 ed. - Piracicaba: FEALQ, 1996. 791p.

21. TERRA, M. M.; PIRES, E. J. P.; POMMER, C. V.; BOTELHO, R. V. Produtividade da cultivar de uva de mesa Niagara Rosada sobre diferentes porta-enxertos, em Monte Alegre do Sul-SP. Revista Brasileira de Fruticultura, Jaboticabal, v.25, n.3, p.546548, 2003.

22. ZONTA, E P., MACHADO. A. A. Sanest: sistema de analise para microcomputadores. Registrado na secretaria especial de informática - SEI - sob no 066-060. Categoria A. Pelotas, RS, 1984.

Recebido em 04/10/2005 Aceito em 21/06/2006 